\title{
Serum inflammatory markers in the diagnosis and assessment of Crohn's disease activity
}

Krystyna Słowińska-Solnica ${ }^{1}$, Dorota Pawlica-Gosiewska ${ }^{1}$, Katarzyna Gawlik ${ }^{1}$, Danuta Owczarek ${ }^{2,3}$, Dorota Cibor ${ }^{2,3}$, Halina Pocztar ${ }^{2,3}$, Tomasz Mach²,3, Bogdan Solnica ${ }^{1}$

\author{
${ }^{1}$ Department of Clinical Biochemistry, Jagiellonian University Medical College, Krakow, \\ Poland \\ 2Department of Gastroenterology and Hepatology, Jagiellonian University Medical \\ College, Krakow, Poland \\ ${ }^{3}$ Department of Gastroenterology and Hepatology, University Hospital, Krakow, \\ Poland
}

Submitted: 20 November 2020

Accepted: 24 November 2020

Arch Med Sci 2021; 17 (1): 252-257

DOI: https://doi.org/10.5114/aoms/130842

Copyright (c) 2020 Termedia \& Banach

\section{Abstract}

Introduction: The aim of our study was to evaluate the diagnostic characteristics of selected inflammatory markers and the results of multiplication of their concentrations in the diagnosis and assessment of Crohn's disease (CD) activity.

Methods: We studied 49 patients with CD and 31 healthy controls. The CD patients were assigned to subgroups with active and inactive disease based on the Crohn's Disease Activity Index score. Serum interleukins and C-reactive protein (CRP) were measured using immunoassays.

Results: Serum CRP and interleukins: IL-6, IL-17A, IL-23 were significantly higher in the $C D$ group than in controls, with the best diagnostic performance for IL-23. Only serum IL-6 and CRP were significantly higher in active than in inactive disease, with the better performance of CRP. Multiplication results did not perform better than individual multipliers.

Conclusions: Serum CRP may be useful in the assessment of CD activity and there is a need for introduction of IL-23 for the CD diagnosis.

Key words: inflammatory bowel disease, cytokines, C-reactive protein, Crohn's disease activity index.

Crohn's disease (CD) is a chronic transmural intestinal inflammation affecting various parts of the gastrointestinal tract. Diagnosis of CD is based on the history and physical examination, imaging studies including magnetic resonance, endoscopy and histology, and laboratory tests $[1,2]$.

Laboratory tests are additional tools in the CD diagnosis and include antibodies to Saccharomyces cerevisiae and inflammatory markers such as erythrocyte sedimentation rate (ESR), serum C-reactive protein (CRP) or interleukin 6 (IL-6), and fecal calprotectin (FC). Except for FC, inflammatory markers are not routinely used in the diagnosis of CD. However, under certain clinical circumstances, these markers may be helpful in differentiating inflammatory bowel disease (IBD) from non-inflammatory disorders such as irritable bowel syndrome and in establishing a further diagnostic strategy.

\author{
Corresponding author: \\ Prof. Bogdan Solnica \\ Department of \\ Clinical Biochemistry \\ Jagiellonian University \\ Medical College \\ Krakow, Poland \\ Phone: +48124214006 \\ E-mail: mbsolnic@cyf-kr. \\ edu.pl
}


The clinical status of $C D$ patients is often assessed using the Crohn's Disease Activity Index (CDAI) calculated using clinical and laboratory data including general well-being, number of abnormal stools, abdominal pain, arthritis/arthralgia, mucocutaneous lesions, iritis/uveitis, fever, hematocrit and others [3]. However, some criteria included in the CDAl are scored by the patients subjectively and some of them may require extended diagnostics, e.g. eyes examination or osteoarticular assessment. Therefore, the use of CDAl can be time consuming, inconvenient for the patient and sometimes not completely reliable. Another approach is endoscopy and cross-sectional imaging techniques with the use of ultrasound, computed tomography and magnetic resonance imaging. However, these diagnostic procedures have several disadvantages [4, 5]. As inflammation plays a key role in the pathogenesis and clinical course of CD, the use of inflammatory markers is another option in assessing disease activity.

Fecal calprotectin and serum CRP are broadly studied and used for CD activity assessment in clinical practice $[6,7]$. However, IL-6, IL-17A and IL-23 (IL-23/IL-17 axis), despite their well-documented role in triggering and maintaining the mucosal inflammation, still remain candidate markers. The availability of simple laboratory tests instead of quite complicated scoring systems and/ or endoscopy could make CD activity assessment easier and faster. Many approaches to use biomarkers for this purpose have been studied with conflicting results [4, 5, 8-12].

In this study, we aimed to evaluate the diagnostic characteristics of selected inflammatory markers including serum CRP, IL-6, IL-17A, IL-23, and the results (products) of multiplication of their concentrations in the diagnosis of CD and in the assessment of disease activity.

Methods. We studied 49 patients with CD, aged from 22 to 50 years and 31 healthy controls aged from 20 to 61 years. The study was conducted in years 2018-2019 and the patients were enrolled consecutively in the Department of Gastroenterology and Hepatology of the University Hospital, Krakow, Poland. The diagnosis of $C D$ was based on the patient's history, physical examination and colonoscopy with histology. All CD patients studied were treated at the time of enrollment. The therapies used included glucocorticoids, 6-mercaptopurine, 5-aminosalicylate, Infliximab and antibiotics. In all CD patients the CDAl score was calculated and they were assigned to subgroups with active (CDAl score $\geq 150$, 33 patients) and inactive (CDAl score < 150, 16 patients) disease. Informed consent was signed by each subject prior to enrolling in the study. The Bioethical Committee of the Jagiellonian University, Krakow, Poland, approved the study.
Serum concentrations of IL-6, IL-17A and IL-23 were measured using ELISA reagent kits. High-sensitivity C-reactive protein (hs-CRP) was measured using the immunonephelometric assay on the Nephelometer II Analyzer (Siemens Healthcare Diagnostics). The results of multiplication of concentrations: [IL-6] $\times[$ CRP], [IL-17A] $\times[$ CRP], [IL-23] $\times$ [CRP], [IL-6] $\times[$ IL-17A], [IL-6] $\times$ [IL-23] and [IL-17A] $\times$ [IL-23] were calculated using standard units (mg/l for CRP, pg/ml for interleukins).

Statistical analysis. Data distribution was analyzed using the Shapiro-Wilk test. All variables in our study showed a nonparametric distribution, and therefore the results are presented as medians and interquartile ranges [Q1-Q3]. Medians were compared using the Kruskal-Wallis Anova test and the Dunn Test. The significance level of $p<0.05$ was applied.

Diagnostic characteristics in differentiating between the presence and absence of $C D$ and between active and inactive disease were assessed using Receiver Operating Characteristics (ROC) curve analysis to select appropriate cut-off values and calculations of diagnostic sensitivity and specificity, positive and negative predictive value, and area under the ROC curve (AUC). All analyzes were performed using the Statistica 13 software (StatSoft Poland).

Results. Serum levels of CRP, IL-6, IL-17A and IL-23 were significantly higher in the CD group than in controls (Table I). In the diagnosis of CD, IL-23 had the most favorable diagnostic characteristics while other markers performed worse with AUC < 0.8 (Table II). All results (products) of multiplication of concentrations differed significantly between CD patients and the control group (Table I). The diagnostic characteristics of these products were better than those of the individual factors, but still the best performance was found for serum IL-23 multiplied by CRP, IL- 6 and IL-17A levels. Also, the performance of [IL-6] × [CRP] was slightly better than that of IL-6 and CRP separately (Table II).

In the group of patients with $C D$, only serum CRP and IL-6 were significantly higher in active than in inactive disease (Table I). In differentiating active and inactive CD with cut-off values other than for the diagnosis, the best diagnostic performance was found for CRP whereas IL-6, IL-17A and IL-23 performed worse. The multiplication of serum levels slightly improved their diagnostic performance as combined markers (Table II).

Discussion. In this study, we evaluated CRP and inflammatory cytokines reported to be associated with CD pathogenesis and clinical course, i.e. IL-6, IL-17A, IL-23 and the results of multiplication of their concentrations as combined markers in the CD diagnosis and disease activity assessment.

We observed serum CRP levels as well as the results of multiplications: [IL-6] $\times[$ CRP], [IL-17A] $\times$ 
Table I. Comparison of median values (IQR) of serum inflammatory makers and the results of multiplication of their concentrations in CD patients and controls and in patients with active and inactive CD

\begin{tabular}{|c|c|c|c|}
\hline \multirow[t]{2}{*}{ Marker } & Crohn's disease $(n=49)$ & Control group $(n=31)$ & \multirow[t]{2}{*}{$P$-value } \\
\hline & \multicolumn{2}{|c|}{ Median (IQR) } & \\
\hline $\mathrm{CRP}[\mathrm{mg} / \mathrm{ll}]$ & $3.48(1.03-20.62)$ & $0.51(0.16-1.74)$ & 0.0001 \\
\hline IL-6 [pg/ml] & $3.24(1.50-7.35)$ & $1.35(0.77-1.96)$ & $<0.0001$ \\
\hline IL-17A [pg/ml] & $2.01(1.26-3.48)$ & $0.93(0.47-1.88)$ & 0.0001 \\
\hline $\mathrm{IL}-23[\mathrm{pg} / \mathrm{ml}]$ & $23.3(18.0-36.0)$ & $5.78(3.70-7.79)$ & $<0.0001$ \\
\hline$[\mathrm{IL}-6] \times[\mathrm{CRP}]$ & $17.8(1.38-111.39)$ & $0.35(0.00-8.34)$ & $<0.0001$ \\
\hline$[\mathrm{IL}-17 \mathrm{~A}] \times[\mathrm{CRP}]$ & $7.18(1.30-40.92)$ & $0.35(0.00-8.34)$ & $<0.0001$ \\
\hline$[I L-23] \times[C R P]$ & $108.22(16.76-579.80)$ & $2.47(0.70-10.32)$ & $<0.0001$ \\
\hline$[\mathrm{IL}-6] \times[\mathrm{IL}-17 \mathrm{~A}]$ & $6.51(2.50-17.39)$ & $1.49(0.01-15.42)$ & $<0.0001$ \\
\hline$[I L-6] \times[I L-23]$ & $93.53(32.86-227.93)$ & $6.71(4.01-13.44)$ & $<0.0001$ \\
\hline$[\mathrm{IL}-17 \mathrm{~A}] \times[\mathrm{IL}-23]$ & $52.10(30.07-109.40)$ & $4.43(2.25-10.75)$ & $<0.0001$ \\
\hline Marker & $\begin{array}{c}\text { Inactive CD } \\
\text { CDAI }<150(n=16)\end{array}$ & $\begin{array}{c}\text { Active CD } \\
\text { CDAI } \geq 150(n=33)\end{array}$ & $P$-value \\
\hline $\mathrm{CRP}[\mathrm{mg} / \mathrm{l}]$ & $1.14(0.46-2.56)$ & $10.85(2.96-28.12)$ & 0.000130 \\
\hline $\mathrm{IL}-6[\mathrm{pg} / \mathrm{ml}]$ & $2.05(1.01-3.20)$ & $4.35(2.16-9.00)$ & 0.025885 \\
\hline IL-17A [pg/ml] & $2.01(1.23-3.34)$ & $2.01(1.26-3.70)$ & 0.639040 \\
\hline IL-23 [pg/ml] & $20.90(16.54-26.82)$ & $26.65(19.36-37.04)$ & 0.132823 \\
\hline$[\mathrm{IL}-6] \times[\mathrm{CRP}]$ & $2.39(0.02-24.66)$ & $41.38(0.04-3388.08)$ & $<0.0001$ \\
\hline$[\mathrm{IL}-17 \mathrm{~A}] \times[\mathrm{CRP}]$ & $2.13(0.50-24.92)$ & $19.97(0.02-557.33)$ & $<0.0001$ \\
\hline$[I L-23] \times[C R P]$ & $21.66(9.33-51.68)$ & $422.15(68.19-790.87)$ & $<0.0001$ \\
\hline$[\mathrm{IL}-6] \times[\mathrm{IL}-17 \mathrm{~A}]$ & $4.40(0.33-35.24)$ & $7.53(0.12-510.44)$ & $<0.0001$ \\
\hline$[\mathrm{IL}-6] \times[\mathrm{L}-23]$ & $43.93(27.62-103.60)$ & $114.26(42.91-268.33)$ & $<0.0001$ \\
\hline$[\mathrm{IL}-17 \mathrm{~A}] \times[\mathrm{IL}-23]$ & $37.10(23.13-83.97)$ & 59.37 (33.19-151.79) & $<0.0001$ \\
\hline
\end{tabular}

$C D$ - Crohn's disease, CDAI - Crohn's disease activity index, IQR - interquartile range.

[CRP], [IL-23] $\times[C R P]$ significantly higher in the CD group than in controls (Table I). However, the performance of serum CRP in the diagnosis of CD was rather poor and only slightly improved after multiplication by IL-6, IL-17A and IL-23 levels (Table II). These findings seem to exclude the use of CRP in the diagnosis of CD. However, the slight differences in serum CRP between the studied group and controls (Table I) and the observed poor diagnostic performance were largely due to by the CD treatment of patients studied, which is a limitation of this analysis.

Serum CRP and FC are the most broadly evaluated and frequently used markers of $C D$ activity $[5,6,13]$. Increased serum CRP levels were reported in patients with $C D$ and associated with the disease activity $[2,6,14,15]$. In our study, serum CRP was significantly higher in CD patients with active than with inactive disease (Table I). CRP had diagnostic sensitivity of 0.72 , which means $72 \%$ agreement with the CDAI, diagnostic specificity and PPV equal to 1.0 and good overall performance (Table II). Multiplication of serum CRP by IL-6, IL-17A and IL-23 levels did not improve diagnostic characteristics of these combined markers. It is noteworthy that similar diagnostic performance was reported for FC [16-18].

Diagnostic performance of CRP found in our study was close to reported in comparison with endoscopic assessment of CD activity [19], when combined with FC for selecting patients with suspected CD of the small bowel for capsule endoscopy [20] and together with CDAl and fecal calprotectin to predict the outcome after anti-tumor necrosis factor (TNF) induction therapy [21]. Altogether, our and published data indicate that serum $\mathrm{CRP}$ reliably assesses the clinical activity of CD.

IL- 6 is considered a central cytokine in the CD pathogenesis and propagation [22, 23]. We found that its serum levels as well as the results of mul- 
Table II. Diagnostic characteristics of serum inflammatory markers and the results of multiplication of their concentrations in the diagnosis of CD and the differentiation of active and inactive disease

\begin{tabular}{|c|c|c|c|c|c|c|}
\hline Marker & Cut-off value & Sensitivity & Specificity & PPV & NPV & AUC \\
\hline \multicolumn{7}{|l|}{ The diagnosis of CD: } \\
\hline $\mathrm{CRP}[\mathrm{mg} / \mathrm{ll}]$ & 2.69 & 0.592 & 0.933 & 0.935 & 0.583 & 0.761 \\
\hline IL-6 [pg/ml] & 2.16 & 0.673 & 0.839 & 0.868 & 0.619 & 0.765 \\
\hline IL-17A [pg/m] & 1.06 & 0.878 & 0.548 & 0.754 & 0.739 & 0.757 \\
\hline $\mathrm{IL}-23[\mathrm{pg} / \mathrm{ml}]$ & 15.02 & 0.959 & 0.968 & 0.979 & 0.938 & 0.994 \\
\hline$[\mathrm{IL}-6] \times[\mathrm{CRP}]$ & 12.7 & 0.571 & 1.000 & 1.000 & 0.596 & 0.791 \\
\hline$[\mathrm{IL}-17 \mathrm{~A}] \times[\mathrm{CRP}]$ & 3.3 & 0.694 & 0.935 & 0.944 & 0.659 & 0.846 \\
\hline$[\mathrm{IL}-23] \times[\mathrm{CRP}]$ & 29.1 & 0.735 & 1.000 & 1.000 & 0.705 & 0.904 \\
\hline$[\mathrm{IL}-6] \times[\mathrm{IL}-17 \mathrm{~A}]$ & 2.5 & 0.776 & 0.774 & 0.844 & 0.686 & 0.799 \\
\hline$[I L-6] \times[L-23]$ & 16.9 & 0.898 & 0.935 & 0.957 & 0.853 & 0.939 \\
\hline$[\mathrm{IL}-17 \mathrm{~A}] \times[\mathrm{IL}-23]$ & 21.4 & 0.857 & 0.935 & 0.955 & 0.806 & 0.947 \\
\hline \multicolumn{7}{|c|}{ The differentiation of active and inactive disease: } \\
\hline $\mathrm{CRP}[\mathrm{mg} / \mathrm{l}]$ & 4.54 & 0.72 & 1.00 & 1.00 & 0.64 & 0.841 \\
\hline $\mathrm{IL}-6[\mathrm{pg} / \mathrm{ml}]$ & 2.78 & 0.70 & 0.75 & 0.85 & 0.55 & 0.699 \\
\hline IL-17A [pg/ml] & 0.99 & 0.94 & 0.19 & 0.71 & 0.60 & 0.543 \\
\hline $\mathrm{IL}-23[\mathrm{pg} / \mathrm{ml}]$ & 15.5 & 0.97 & 0.19 & 0.71 & 0.75 & 0.634 \\
\hline$[\mathrm{IL}-6] \times[\mathrm{CRP}]$ & 19.6 & 0.70 & 0.94 & 0.96 & 0.60 & 0.801 \\
\hline$[\mathrm{IL}-17 \mathrm{~A}] \times[\mathrm{CRP}]$ & 7.2 & 0.73 & 0.94 & 0.96 & 0.63 & 0.822 \\
\hline$[\mathrm{IL}-23] \times[\mathrm{CRP}]$ & 0.77 & 1.00 & 0.06 & 0.69 & 1.00 & 0.854 \\
\hline$[\mathrm{IL}-6] \times[\mathrm{IL}-17 \mathrm{~A}]$ & 0.80 & 0.94 & 0.25 & 0.72 & 0.67 & 0.618 \\
\hline$[\mathrm{IL}-6] \times[\mathrm{L}-23]$ & 50.1 & 0.73 & 0.63 & 0.80 & 0.53 & 0.712 \\
\hline$[\mathrm{IL}-17 \mathrm{~A}] \times[\mathrm{IL}-23]$ & 12.7 & 0.97 & 0.13 & 0.70 & 0.67 & 0.616 \\
\hline
\end{tabular}

$C D$ - Crohn's disease, NPV - negative predictive value, PPV - positive predictive value, AUC - area under the ROC curve.

tiplication of concentrations were significantly higher in patients with $C D$ than in controls. The performance of IL- 6 in the CD diagnosis was better than CRP and multiplication [IL-6] $\times$ [CRP] improved it slightly but still with AUC $<0.8$ (Table II). With a similar limitation as in the case of CRP, the overall diagnostic performance of IL- 6 is inferior to that required for clinical practice purposes.

IL-6 is also a candidate marker for CD course and treatment monitoring. It was demonstrated to be associated with disease activity [22-25], to predict endoscopic IBD activity in combination with serum amyloid A (SAA), IL-8, and eotaxin-1 [26], and to predict the response to biologic treatment in CD patients $[27,28]$. However, there are also reports that do not confirm the diagnostic utility of IL-6 in CD [29]. We found serum IL-6 significantly higher in $C D$ patients with active than inactive disease (Table I). The ratio of median serum IL-6 in active and inactive CD of 2.12 was similar to that reported by Mavropoulou et al. [25], but lower than in a study by Nikolaus et al. [24]. Diagnostic performance of IL-6 in differentiating active and inactive disease was in our study worse than that of CRP (Table II).

CRP is synthetized and secreted by hepatocytes under the influence of IL-6, and their serum levels usually correlate. We evaluated diagnostic characteristics of the results of multiplication [IL-6] $\times$ [CRP]. The values of this combined marker differed significantly between patients with active and inactive $C D$, and its diagnostic performance was better than that of IL-6 but worse than that of CRP (Tables I, II). In conclusion, contrary to the published data mentioned above, IL-6 is not a suitable single marker also for the differentiation of active and inactive CD.

Th17 cells and the IL-17/IL-23 axis play an important role in the pathogenesis and clinical course of CD [30, 31]. Additionally, IL-6 and IL-17 are inflammatory mediators produced by activated Th17 cells [32]. However, evidence for the 
diagnostic utility of IL-17 and IL-23 in CD/IBD is scarce and reports are discordant [33-35]; more attention is paid to these cytokines as a therapeutic target [36, 37]. In our study, serum IL-17A and IL-23 as well as the results of multiplication of their concentrations were significantly higher in treated CD patients compared to controls. In the diagnosis of CD serum IL-23 performed best among all studied markers, while the diagnostic characteristics of IL-17A were comparable to those of IL-6 (Table I). The diagnostic performance of the multiplication results was markedly better than that of serum CRP and IL- 6 but still slightly worse than with IL-23 as a single marker (Table II). The diagnostic performance of IL-23 may be related to the involvement of the IL-17/IL-23 axis in CD pathogenesis. However, this was not the case with IL-17A and IL-6.

Interestingly, serum levels of IL-17A and IL-23 did not differ significantly between CD patients with active and inactive disease, but their multiplication results did (Table I). The performance of IL$17 \mathrm{~A}$ and IL-23 in differentiating active and inactive CD was poor (Table II). Multiplying serum levels of IL-17A and IL-23 by CRP made the diagnostic performance of these combined markers comparable to CRP (Table II). Thus, both IL-17A and IL-23 cannot be recommended as markers of CD activity.

Laboratory markers of inflammation are hardly used in the diagnosis of $C D$ and the assessment of its activity. We found good performance characteristics of IL-23 in the diagnosis of CD and CRP in the assessment of disease activity. We also evaluated the results of multiplication of concentrations as combined inflammatory markers, but their diagnostic performance was not better compared to the individual multipliers to a degree authorizing their use in clinical practice.

Measurement of inflammatory markers in serum can be performed together with other tests necessary for care of CD patients, such as complete blood count or serum albumin. In general, laboratory markers used instead of or in selecting patients for endoscopy or other imaging studies could make the CD diagnosis and the assessment of its activity easier, more convenient and less expensive. Promising diagnostic performance of CRP and IL-23 found in our study in a relatively small group of $C D$ patients should be considered preliminary. It has to be emphasized, however, that currently CRP is measured routinely, while the IL-23 ELISA reagent kits are approved for research use only. Thus, our results suggest the utility of serum CRP in assessment of $\mathrm{CD}$ activity, and the need for validation and approval of IL-23 assays for the CD diagnosis.

\section{Conflict of interest}

The authors declare no conflict of interest.

\section{References}

1. Feuerstein JD, Cheifetz AS. Crohn disease: epidemiology, diagnosis, and management. Mayo Clin Proc 2017; 92: 1088-1103.

2. Baumgart DC, Sandborn WJ. Crohn's disease. Lancet 2012; 380: 1590-606

3. Best WR, Becktel JM, Singleton JW, Kern F Jr. Development of a Crohn's disease activity index. National Cooperative Crohn's Disease Study. Gastroenterology 1976; 70: 439-44.

4. Bourgonje AR, von Martels JZH, Gabriëls RY, et al. A combined set of four serum inflammatory biomarkers reliably predicts endoscopic disease activity in inflammatory bowel disease. Front Med 2019; 6: 251.

5. Benitez JM, Meuwis MA, Reenaers C, Van Kemseke C, Meunier P, Louis E. Role of endoscopy, cross-sectional imaging and biomarkers in Crohn's disease monitoring. Gut 2013; 62: 1806-16.

6. Ma C, Battat R, Parker CE, Khanna R, Jairath V, Feagan BG. Update on C-reactive protein and fecal calprotectin: are they accurate measures of disease activity in Crohn's disease? Expert Rev Gastroenterol Hepatol 2019; 13: 319-30.

7. Chang S, Malter L, Hudesman D. Disease monitoring in inflammatory bowel disease. World I Gastroenterol 2015; 21: 11246-59.

8. Singha UP, Singha NP, Murphya EA, et al. Chemokine and cytokine levels in inflammatory bowel disease patients. Cytokine 2016; 77: 44-9.

9. Hoekman DR, Diederen K, Koot BGP, Tabbers MM, Kindermann A, Benninga MA. Relationship of clinical symptoms with biomarkers of inflammation in pediatric inflammatory bowel disease. Eur J Pediatr 2016; 175: 1335-42.

10. Vermeire S, Van Assche G, Rutgeerts P. Laboratory markers in IBD: useful, magic, or unnecessary toys? Gut 2006; 55: 426-31.

11. Szczeklik K, Mach T, Cibor D, et al. Correlation of paraoxonase- 1 with the severity of Crohn's disease. Molecules 2018; 23: 2603.

12. Szczeklik K, Krzyściak W, Cibor D, et al. Markers of lipid peroxidation and antioxidant status in the serum and saliva of patients with active Crohn disease. Pol Arch Intern Med 2018; 128: 362-70.

13. Mak LY, Tong TSM, Cheung KS, et al. Combined use of common fecal and blood markers for detection of endoscopically active inflammatory bowel disease. Clin Transl Gastroenterol 2020; 11: e00138.

14. Shiga H, Abe I, Onodera M, et al. Serum C-reactive protein and albumin are useful biomarkers for tight control management of Crohn's disease in Japan. Sci Rep 2020; 10: 511 .

15. Chang S, Malter L, Hudesman D. Disease monitoring in inflammatory bowel disease. World J Gastroenterol 2015; 21: 11246-59.

16. Vázquez-Morón JM, Pallarés-Manrique H, Machancoses FH, Ramos-Lora M, Ruiz-Frutos C. Accurate cut-offs for predicting endoscopic activity and mucosal healing in Crohn's disease with fecal calprotectin. Rev Esp Enferm Dig 2017; 109: 130-6.

17. Scaioli E, Cardamone C, Scaglmiarini M, Zagari RM, Bazzoli F, Belluzzi A. Can fecal calprotectin better stratify Crohn's disease activity index? Ann Gastroenterol 2015; 28: 247-52.

18. Sipponen T, Savilahti E, Kolho KL, Nutinen H, Turunen U, Färkkilä M. Crohn's disease activity assessed by fecal calprotectin and lactoferrin: correlation with Crohn's 
Disease Activity Index and endoscopic findings. Inflamm Bowel Dis 2008; 14: 40-6.

19. Mitselos IV, Katsanos KH, Tatsioni A, et al. Association of clinical and inflammatory markerswith small bowel capsule endoscopy findings in Crohn's disease. Eur J Gastroenterol Hepatol 2018; 30: 861-7.

20. Egea-Valenzuela J, Pereñíguez-López A, Pérez-Fernández V, Alberca-de-las-Parras F, Carballo-Álvarez F. Fecal calprotectin and C-reactive protein are associated with positive findings in capsule endoscopy in suspected small bowel Crohn's disease. Rev Esp Enferm Dig 2016; 108: 394-400.

21. Sollelis E, Quinard RM, Bouguen G, et al. Combined evaluation of biomarkers as predictor of maintained remission in Crohn's disease. World J Gastroenterol 2019; 25: 2354-64.

22. Mudter J, Neurath MF. IL-6 Signaling in inflammatory bowel disease: pathophysiological role and clinical relevance. Inflamm Bowel Dis 2007; 13: 1016-23.

23. Takač B, Mihaljević S, Štefanić M, Glavas-Obrovac L, Kibel A, Samardzija M. Importance of interleukin 6 in pathogenesis of inflammatory bowel disease. Coll Antropol 2014; 38: 659-64.

24. Nikolaus S, Waetzig GH, Butzin S, et al. Evaluation of interleukin- 6 and its soluble receptor components SIL-6R and sgp130 as markers of inflammation in inflammatory bowel diseases. Int J Colorectal Dis 2018; 33: 927-36.

25. Mavropoulou E, Mechie NC, Knoop R, et al. Association of serum interleukin- 6 and soluble interleukin-2-receptor levels with disease activity status in patients with inflammatory bowel disease: a prospective observational study. PLoS One 2020; 15: e0233811.

26. Bourgonje AR, von Martels JZH, Gabriëls RY, et al. A combined set of four serum inflammatory biomarkers reliably predicts endoscopic disease activity in inflammatory bowel disease. Front Med 2019; 6: 251.

27. Caviglia GP, Rosso C, Stalla F, et al. On-treatment decrease of serum interleukin- 6 as a predictor of clinical response to biologic therapy in patients with inflammatory bowel diseases. J Clin Med 2020; 9: 800.

28. Suzuki Y, Matsui T, Ito H, et al. Circulating interleukin 6 and albumin, and infliximab levels are good predictors of recovering efficacy after dose escalation infliximab therapy in patients with loss of response to treatment for Crohn's disease: a prospective clinical trial. Inflamm Bowel Dis 2015; 21: 2114-22.

29. Nancey S, Hamzaoui N, Moussata D, et al. Serum interleukin-6, soluble interleukin-6 receptor and Crohn's disease activity. Dig Dis Sci 2008; 53: 242-7.

30. Ruiz de Moralesa JMG, Puig L, Daudén E, et al. Critical role of interleukin (IL)-17 in inflammatory and immune disorders: an updated review of the evidence focusing in controversies. Autoimmun Rev 2020; 19: 102429.

31. Cătană CS, Berindan Neagoe I, Cozma V, Magdaş C, Tăbaran F, Dumitraşcu DL. Contribution of the IL-17/ IL-23 axis to the pathogenesis of inflammatory bowel disease. World I Gastroenterol 2015; 21: 5823-30.

32. Yen D, Cheung J, Scheerens $\mathrm{H}$ et al. IL-23 is essential for $\mathrm{T}$ cell-mediated colitis and promotes inflammation via IL-17 and IL-6. J Clin Invest 2006; 116: 1310-6.

33. Sahin A, Calhan T, Cengiz M, Kahraman R, et al. Serum interleukin 17 levels in patients with Crohn's disease: real life data. Dis Markers 2014; 2014: 690853.

34. Liu QL, Huang L, Zhao QJ, Li Q, He Z. Relationship between serum interleukin-17 level and inflammatory bowel disease. J Biol Regul Homeost Agents 2016; 30: 181-8.
35. Karczewski J, Swora-Cwynar E, Rzymski P, Poniedziatek B, Adamski Z. Selected biologic markers of inflammation and activity of Crohn's disease. Autoimmunity 2015; 48: 318-27.

36. Moschen AR, Tilg H, Raine T. IL-12, IL-23 and IL-17 in IBD: immunobiology and therapeutic targeting. Nat Rev Gastroenterol Hepatol 2019; 16: 185-96.

37. Furfaro F, Gilardi D, Allocca M, et al. IL-23 blockade for crohn s disease: next generation of anti-cytokine therapy. Expert Rev Clin Immunol 2017; 13: 457-67. 